\title{
Penerimaan Pengguna Instagram terhadap Analogi Visual Seksualitas dengan Makanan oleh Influencer Instagram
}

\author{
Intan Rigita Risti Fauzia \\ Departemen Ilmu Komunikasi, Universitas Airlangga, Jalan Jalan Dharmawangsa Dalam No. \\ 4-6 Surabaya 60286, Indonesia. Email: intanrigita@gmail.com
}

\begin{abstract}
A B S T R A C T
This research focuses on the acceptance of Instagram users to the visual analogy of sexuality with food by Instagram influencers when delivering sex education material that is still considered taboo in Indonesia. By using a qualitative approach and a type of descriptive research, this research focuses on the meaning received by the nine informants who have participated. The research method used is Reception Analysis with in-depth interviews as data collection technique. The literature review used is a visual analogy to explain the taboo about sexuality, sexuality in Indonesia, problems of formal sex education, symbolic construction of sexuality in traditional media, and sexuality content that appears on Instagram social media. The findings of this study indicate that the informants interpret the visual analogy of sexuality based on the concept of heteronormativity in everyday life. Then, stereotypes about sexuality that develop in the community also become a reference when they answer questions. The perception of the state of Indonesia as homophobic and transphobic country, but when faced with a visual analogy in the form of food, the informants did not object to the existence of LGBT groups or to the concept of homosexuality.
\end{abstract}

Keywords: visual analogy; food; taboo; sex education; reception analysis.

\section{A B S T R A C T}

Penelitian ini berfokus pada penerimaan pengguna Instagram terhadap analogi visual seksualitas dengan makanan oleh influencer Instagram ketika menyampaikan materi pendidikan seks yang masih dianggap tabu di Indonesia. Dengan menggunakan pendekatan kualitatif dan tipe penelitian deskriptif, penelitian ini berfokus pada pemaknaan yang diterima oleh sembilan informan yang telah berpartisipasi. Metode penelitian yang digunakan adalah Reception Analysis dengan in-depth interview sebagai teknik pengumpulan data. Tinjauan pustaka yang digunakan adalah analogi visual untuk menjelaskan ketabuan seksualitas, seksualitas di Indonesia, problematika pendidikan seks formal, konstruksi simbolis seksualitas dalam media tradisional, serta konten seksualitas yang muncul di media sosial Instagram. Hasil temuan dari penelitian ini menunjukkan bahwa para informan memaknai analogi visual seksualitas berdasar pada konsep heteronormativitas pada kehidupan sehari-hari. Kemudian, stereotip mengenai seksualitas yang berkembang di masyarakat juga menjadi rujukan ketika mereka menjawab pertanyaan. Anggapan negara Indonesia masih homophobic dan transphobic, namun ketika dihadapkan pada analogi visual berupa makanan, para informan tidak merasa keberatan dengan adanya kelompok LGBT maupun dengan konsep homoseksualitas.

Kata kunci : analogi visual; makanan; tabu; pendidikan seks; analisis resepsi.

\section{A. PENDAHULUAN}

Penelitian ini bertujuan untuk menganalisa bagaimana penerimaan khalayak terhadap ragam analogi visual organ intim dan aktivitas seksual dengan makanan oleh influencer Instagram. Penggunaan analogi visual berupa makanan, seperti donat dan pisang untuk menggambarkan organ intim dan aktivitas seksual menjadi menarik untuk diteliti. Instagram yang awalnya digunakan untuk berbagi kegiatan sehari-hari, kemudian menjadi medium untuk berdiskusi dan menyampaikan materi pendidikan seks.

Pembahasan mengenai pendidikan seks masih sangat minim dikarenakan anggapan ketabuan yang melingkupinya. Beberapa kelompok masyarakat meyakini bahwa pendidikan seks atau halhal seksual merupakan hal yang privat dan tidak perlu diungkapkan secara terbuka. Padahal 
menurut Ernawan seks memiliki hubungan yang erat dengan paradigma yang bersifat nature dan nurture. Bersifat nature dilihat melalui sudut pandang bahwa fenomena seks sebagai pemberian dari Tuhan, sedangkan yang bersifat nurture melihat seks sebagai fenomena konstruksi sosial (Ernawan, 2009).

Melalui pengalaman peneliti, materi pendidikan seks tidak dikenalkan secara khusus dalam sistem pendidikan formal, melainkan melalui materi dasar, seperti biologi dan kesehatan jasmani. Selain itu, pendidikan seks di Indonesia yang masih belum memadai membuat masyarakat masih enggan untuk membahas hal-hal seksual, bahkan untuk menyebut perbedaan organ intim. Perumpamaan-perumpamaan, seperti analogi visual biasanya digunakan untuk menyampaikan materi tersebut. Hal tersebut menimbulkan ketakutan atau rasa malu ketika akan membahas pendidikan seks atau hal-hal seksual secara terbuka.

Pendidikan seks yang diberikan di sekolah hanya berupa kesehatan reproduksi dan seksual remaja, namun terbatas pada aspek biologis saja. Pendekatan seperti yang dijabarkan dalam studi yang berjudul "Antara Kebutuhan dan Tabu: Pendidikan Seksualitas dan Kesehatan Reproduksi bagi Remaja di SMA", mengakibatkan konstruksi seksualitas remaja sebagai hal tabu dan berbahaya yang dikontrol melalui wacana moral dan agama (Pakasi \& Kartikawati, 2013).

Di Indonesia, beberapa kelompok masyarakat masih menganut nilai-nilai ketimuran dan didominasi oleh ajaran-ajaran agama. Nilai-nilai tersebut juga mengatur tingkah laku seksual masyarakat atau yang berhubungan dengan seks normatif. Konsep seks normatif merupakan nilainilai yang telah terinstitusionalisasi dalam kehidupan masyarakat dan konsep tersebut dilihat sebagai rujukan masyarakat dalam menjalankan kehidupan seksualnya.

Dari hal tersebut, maka pendidikan seks diperlukan. Pendidikan seks merupakan suatu usaha untuk meningkatkan kesadaran dan memberi informasi untuk masalah seksual yang diberikan pada anak-anak, sehingga mereka mengetahui isu-isu apa saja yang berkaitan dengan seks, insting, dan pernikahan (Tirtawinata, 2016). Wacana pendidikan seks secara formal masih terdapat pro-kontra di dalamnya. Sebagian kelompok masyarakat Indonesia mengganggap pemberian pendidikan seks pada anak usia sekolah dasar (6-12 tahun) masih terlalu dini. Padahal, pendidikan seks perlu diberikan sedini mungkin agar anak atau remaja bisa memahami tubuhnya dengan baik (Suhari, 2011).

Dahulu, pendidikan seks masih tidak perlu diberikan secara karena perempuan biasanya melalui proses dipingit, lalu menjadi ibu rumah tangga yang patuh di rumah, dan merasa wajar jika suaminya kawin lagi, serta tidak ada yang mempermasalahkan atau mengeluh tentang orgasme (Djiwandono, 2008).

Namun, pada abad 20, menurut Gagnon dan Simon, konsep kelas pendidikan seks ialah "guru menyampaikan pencegahan kehamilan yang aman dengan cara seperti menangani barang yang bisa meledak" (Djiwandono, 2008). Kekhawatiran pada peningkatan minat anak-anak muda untuk melakukan kegiatan seks secara aktif menjadi alasan para pendidik dan orang tua takut untuk menyampaikannya. Bahan bacaan juga dipenuhi hubungannya dengan masalah moral dan kerap kali penuh dengan informasi yang kurang tepat.

Alasan lain yang membuat beberapa kelompok masyarakat kontra dengan pendidikan seks adalah pendidikan seks yang tidak bermutu bisa jadi mengancam anak-anak, kekhawatiran pencampuran antara masalah pribadi atau masalah seksual pendidik akan menjadi refleksi pada mutu dan isi pengajaran pendidikan seks, kualifikasi pendidik ketika menyampaikan materi, kekhawatiran perbedaan nilai-nilai pendidikan seks yang ada di rumah dengan di sekolah, perpindahan pendidikan seks dari rumah ke sekolah dilihat sebagai ancaman pada kestabilan keluarga dan masyarakat secara luas, melibatkan orang tua pada perkembangan pendidikan seks 
akan menghambat peran anak-anak karena kemampuan dapat menjadi terbatas, pendidikan seks tidak diberikan pada zaman dahulu dan hal tersebut tidak membuat orang tua menjadi jelek (Djiwandono, 2008).

Tujuan pendidikan seks, menurut Voss, "harus memberikan informasi yang tepat dan mengganti konsepsi yang keliru" (Djiwandono, 2008). Terdapat dua ragam program pendidikan seks, yaitu comprehensive sexuality education dan abstinence-only-until-marriage. Perbedaan yang mencolok terlihat pada penyampaian program bahwa comprehensive lebih pada safe sex, sedangkan abstinence-only-until-marriage cenderung menekankan pada penahanan nafsu (abstinence) sampai pada pernikahan.

Wacana pendidikan seks formal yang masih menimbulkan pro-kontra di masyarakat, mulai ramai diperbincangkan di media sosial, termasuk Instagram. Instagram memberikan akses pada pengguna untuk dapat melihat foto dan video milik sendiri, maupun milik orang lain dengan tujuan membagikan kegiatan sehari-hari pemilik akun, kemudian menjadi medium untuk pemberian pendidikan seks atau medium untuk berdiskusi mengenai hal tersebut.

Dalam penyampaian materi pendidikan seks digunakan analogi visual karena anggapan ketabuan yang masih melingkupinya. Kemampuan individu untuk bisa menganalogikan organ intim dan aktivitas seksual sesuai standar norma masyarakat dibutuhkan, salah satunya dengan menggunakan analogi berupa makanan. Pemberian pendidikan seks pada anak dirasa cukup sulit untuk orang tua karena mereka masih menganggap bahwa membicarakan mengenai seks adalah hal yang tabu (Safita, 2013).

Dalam sejarahnya, seksualitas pada abad ke-17 cukup terbuka, kemudian menjadi terbatas pada masa kelompok borjuis Victoria (Foucault, 1976). Sehingga, sampai saat ini pesan diolah sedemikian rupa untuk menyampaikan materi pendidikan seks. Penggunaan gambar sebagai analogi atau penggantian bahasa yang digunakan menjadi alternatif (metafora).

Pembicaraan seksualitas di Indonesia seringkali dipandang dari sudut moralitas (Redaksi, 2018). Nilai-nilai budaya ketimuran dan ajaran agama yang masih tinggi menjadi alasannya, yang mana menyebabkan beberapa kelompok masyarakat cukup takut membahas hal-hal seksual. Padahal, pembahasan pendidikan seks atau hal-hal seksualitas dan kesehatan reproduksi merupakan hal-hal dasar yang penting untuk dipelajari sejak dini untuk menghindari tindakantindakan pelecehan dan meningkatkan kesadaran untuk menjaga kesehatan organ-organ reproduksi.

Pendidikan seks menjadi penting untuk diberikan di sekolah agar membantu anak muda untuk mengetahui topik-topik biologis, seperti pertumbuhan, masa puber, dan kehamilan; mencegah anak-anak dari tindak kekerasan, mengurangi rasa bersalah, rasa malu, dan kecemasan akibat tindakan seksual; mencegah remaja perempuan dibawah umur dari kehamilan; mendorong hubungan yang baik; mencegah remaja dibawah umur terlibat dalam hubungan seksual (sexual intercourse); mengurangi kasus infeksi melalui seks; membantu anak muda mengetahui peran lakilaki dan perempuan di masyarakat (Halstead \& Reiss, 2004).

Pemberian pendidikan seks bisa dilakukan sesuai usia dan dapat dimulai sejak dini. Orang tua berperan dalam pemberian pengetahuan, semisal dimulai dari mengenal tubuh manusia. Namun dalam beberapa kasus, orang tua enggan membahas pendidikan seks di rumah, sehingga sekolah menjadi tumpuan utama. Hal tersebut juga masih menjadi kekhawatiran orang tua dikarenakan "materi pendidikan seks di Indonesia masih sangat abstrak dan tak jelas juntrungannya" (Wargadiredja, 2017). Lebih jauh lagi, hal-hal seksual masih dianggap suatu rahasia sehingga individu malu jika mengungkapkannya secara terbuka . 
Informasi mengenai pendidikan seks masih sulit untuk diakses para anak-anak atau remaja, sehingga menimbulkan rasa penasaran yang mana memicu mereka untuk mengeksplorasi hal tersebut secara mandiri. Semisal, melalui internet dan tanpa bimbingan yang memadai, sehingga bisa saja akan menjadi masalah baru dalam kehidupan remaja.

Selanjutnya, menilik perkembangan seksualitas di Indonesia, perkembangan tersebut dapat terlacak melalui media tradisional yang ada, seperti media konvensional berupa film dan media cetak berupa majalah. Film sebagai bentuk kesenian dapat menjadi sarana pembangunan konstruksi seksualitas pada masyarakat, sedangkan majalah kerap kali mengangkat isu-isu seksualitas sehingga informasi mengenai seksualitas dapat diterima.

Pembahasan seksualitas di film atau majalah, mulai berkembang sampai pada ranah media sosial. Media sosial didefinisikan sebagai "forms of electronic communication through which users create online communities to share information, ideas, personal messages, and other content" (Jones et al., 2014). Instagram, sebagai salah satu media sosial, menjadi medium informal untuk para anak-anak atau remaja mencari informasi mengenai pendidikan seks. Beberapa akun influencer muncul yang mana membahas mengenai pendidikan seks dan hal-hal seksual dengan khalayak yang lebih luas.

Dalam penelitian ini, fokus peneliti terdapat pada penggunaan ragam analogi visual berupa makanan pada beberapa akun influencer Instagram untuk menyampaikan dan mendiskusikan pendidikan seks maupun hal-hal seksual lainnya, yang mana kemudian analogi visual tersebut dimaknai oleh para informan berdasar praktik wacana dan budaya yang dimilikinya.

\section{B. METODE}

Penelitian ini menggunakan pendekatan kualitatif dengan tipe penelitian deskriptif. Kemudian, untuk menjawab rumusan masalah yang ada dalam penelitian ini, peneliti menggunakan metode analisis resepsi. Metode analisis resepsi adalah sebuah cara untuk "mengkaji proses aktual dimana wacana media diasimilasikan melalui praktik wacana dan budaya khalayaknya" (Shanti, 2015). Selain itu, analisis resepsi khalayak "memahami proses pembuatan makna (making-meaning process) yang dilakukan audiens ketika mengonsumsi tayangan sinema atau program film seri di televisi" (Ida, 2014). Analisis resepsi bertujuan untuk melihat dan memahami respon, penerimaan, sikap, dan makna yang diproduksi atau dibentuk oleh penonton atau pembaca.

Terdapat objek penelitian berupa analogi visual dari organ intim dan aktivitas seksual dengan makanan yang diambil dari beberapa akun influen informan yang berpartisipasi dalam penelitian ini. Subjek penelitian merupakan pengguna media sosial yang mengetahui atau mengikuti salah satu atau beberapa akun influencer di Instagram yang membahas mengenai pendidikan seks dalam unggahan atau highlight story-nya. Terdapat variasi berupa jenis kelamin, usia, pekerjaan, dan pendidikan.

Pada penelitian ini, teknik pengumpulan data yang digunakan adalah in-depth interview atau wawancara mendalam. Teknik tersebut dipilih agar peneliti dapat mengetahui secara menyeluruh penerimaan para informan pada ragam analogi visual organ intim dan aktivitas seksual yang disajikan.

\section{HASIL DAN PEMBAHASAN \\ 1. Donat dan Stereotip yang Melingkupi Vagina}




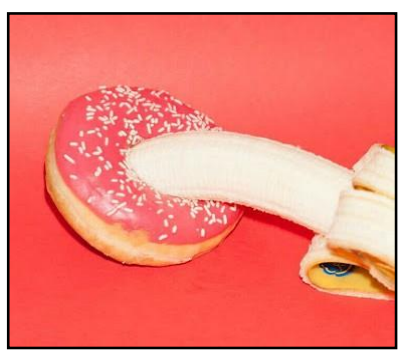

Sumber: Gjerstad

Gambar 1. Donat sebagai Vagina

Gambar 1 dimaknai beberapa informan, seperti Informan 1 'NA' dan Informan 2 'Salsha' sebagai analogi visual dari vagina karena terdapat lubang di tengah donat yang menyerupai penggambaran alat reproduksi wanita tersebut. Penyebutan lubang pada donat sebagai analogi visual vagina terlihat sangat sederhana. Padahal, vagina tidak hanya sekedar 'lubang'.

Kemudian, Informan 3 'HH' dan Informan 6 'Gatra' berfokus pada warna pink serta 'meses warna-warni' yang melingkupi donat tersebut. Tampilan warna pink dihubungkan dengan warna perempuan. Dari hal tersebut terlihat adanya konstruksi sosial pada suatu warna yang digunakan untuk merujuk suatu gender tertentu. Di Indonesia, masyarakat masih mengasosiasikan warna pink sebagai warna untuk perempuan. Selain itu, dengan adanya asosiasi tersebut, dapat memunculkan stereotip bahwa vagina juga berwarna pink. Namun faktanya, warna vagina yang normal memiliki warna gelap secara alami disebabkan oleh hormon esterogen dan testoteron yang naik sehingga menghasilkan melanin (Fitriyani, n.d.-b)

\section{Tabu Pengucapan Lisan Kata 'Vagina' dan 'Penis'}

Dengan minimnya pembahasan mengenai pendidikan seks, berdampak juga pada penyebutan organ intim oleh individu. Seperti pada Informan 1 ' $N A$ ' yang merasa nyaman dengan penggambaran gambar 1, namun ketika mendengar vagina diucapkan secara langsung, ia merasa tidak nyaman. Selain itu, terdapat Informan 9 'Ari' yang menyebutkan organ intim laki-laki dengan perumpaan lain. Ia menyebut penis dengan kata ganti 'Mr. P', dimana terlihat bahwa pengucapannya juga masih cukup tabu sama seperti vagina. Peneliti menghubungkan dengan peran orang tua atau keluarga serta paparan informasi yang ia dapat selama ini mengenai pendidikan seks yang masih minim dan cenderung tertutup.

Keluarga beberapa informan yang tidak pernah membahas masalah pendidikan seks atau pengenalan organ intim secara terbuka menjadikan kurang leluasanya informan ketika mengungkapkan pendapat. Hal tersebut dapat dipahami karena pembahasan mengenai seksualitas wanita masih menjadi topik yang tertutup dan memalukan. Seperti pada studi yang berjudul "Flower Symbolism as Female Sexual Metaphor", "women are taught that their genitalia are unclean or shameful, and should be covered to and avoided at all times" (Frownfelter, 2010).

Beberapa wanita juga masih merasa malu dan takut, serta tidak sepenuhnya tahu terhadap bagian tubuh yang dimilikinya. Munculnya perasaan malu, takut, dan bersalah tersebut dikarenakan adanya peraturan norma gender di masyarakat ketika menyebut organ intim. Selain itu, ajaran agama yang dianut kemudian juga menjadi alasan mereka menahan keinginan untuk mencari tahu lebih lanjut (Frownfelter, 2010). 
Vagina dan penis sebagai bagian dari tubuh manusia harusnya juga disebut sebagaimana aslinya, namun dengan adanya aturan norma dan konstruksi sosial yang ada, menjadikan penyebutan 'vagina' dan 'penis' dihilangkan atau dapat menimbulkan rasa tidak nyaman, takut, dan malu ketika menyebutkannya.

\section{Pisang dan Stigma atas Bentuk dan Ukuran Penis}

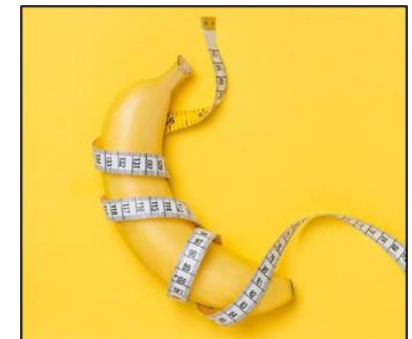

Sumber: iStock dalam Sagita

Gambar 2. Pisang sebagai Penis

Para informan memaknai gambar 2 sebagai bentuk analogi visual penis karena memiliki bentuk lurus dan panjang. Bentuk penis yang lurus dan panjang merupakan sebuah stereotip yang berkembang di masyarakat. Di Indonesia, masyarakat masih mempercayai bahwa laki-laki memiliki penis yang seharusnya lurus dan panjang.

Padahal, penis memiliki beberapa bentuk yang jarang diketahui. Menurut Dr. David Shusterman, ketebalan dan panjang pendek sebuah penis bergantung pada faktor genetis (Fitriyani, n.d.-a). Selain itu, terdapat catatan etnografi yang menujukkan bahwa "averaged the ethnographic data on erect penis size and found them to approximate: Orientals, 4" to 5.5" in length and 1.25" in diameter; Caucasians, 5.5" to 6" in length and 1.3" to 1.6" in diameter; Blacks, 6.25" to 8" in length and 2" in diameter" (Rushton, 1988).

Kemudian, jika dihubungkan, bentuk dan ukuran penis tidak terlepas dengan citra tubuh lakilaki. Banyak laki-laki yang meremehkan ukuran dari penisnya dan percaya bahwa penisnya memiliki ukuran yang lebih kecil dari rata-rata (Tiggemann et al., 2008). Masalah citra tubuh pada laki-laki terkait bagian tubuh tertentu menjadi lebih umum dan mereka mulai mencari perawatan maupun produk yang bisa memperbaiki hal tersebut.

\section{Penetrasi Pisang ke Lubang Donat dan Persepsi Heteronormativitas}

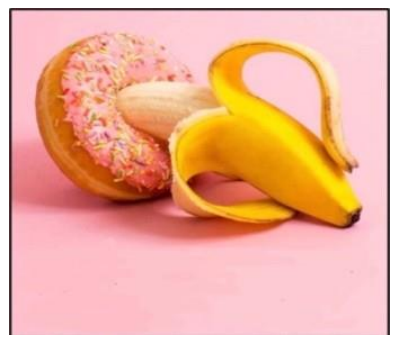

Sumber: @IK

Gambar 3. Lubang Donat Dimasuki Pisang 
Gambar 3 yang menunjukan penggabungan antara donat dengan buah pisang dimaknai para informan sebagai bentuk aktivitas seksual, yaitu hubungan seksual. Donat yang memiliki lubang di tengah diasosiasikan sebagai vagina, dimasuki pisang yang diasosiasikan dengan penis menjadi alasan mengapa para informan memaknai gambar 3 sebagai bentuk hubungan seksual.

Hubungan seksual adalah "kontak seksual yang dilakukan berpasangan dengan lawan jenis atau sesama jenis (Perkumpulan keluarga berencana indonesia, 2016). Penggunaan analogi pada aktivitas seksual, dalam hal ini hubungan seksual, tidak hanya terjadi di Indonesia saja. Hal tersebut terjadi karena kata-kata yang berhubungan dengan seks selalu dihubungkan dengan kerahasiaan, suatu hal yang menjijikkan, dan tidak sesuai dengan nilai moral yang ada (Hongxu, H., \& Guisen, 1990).

Dalam memaknai gambar 3, para informan langsung merujuk pada hubungan seksual yang dilakukan oleh perempuan dan laki-laki dengan penyebutan organ intimnya, yaitu vagina dan penis. Hal tersebut dapat dihubungkan dengan konstruksi sosial dalam masyarakat yang menganggap aktivitas seksual selalu dilakukan antara pasangan berjenis kelamin laki-laki dan perempuan.

Heteronormativitas yang masih kental di dalam masyarakat Indonesia menjadi salah satu alasannya. Didefiniskan sebagai "sebuah konstruksi sosial yang menunjukkan bahwa hubungan seksual yang sesuai norma adalah heteroseksual" menjadikan hubungan seksual antara laki-laki dan perempuan sebagai standar yang ada di masyarakat (Arianita, 2012).

\section{Visual Pisang Berpelukan dan Persepsi atas Homoseksualitas}

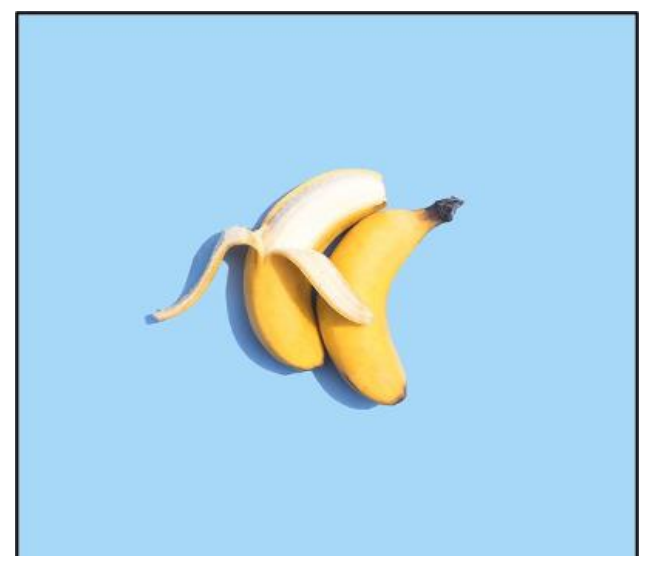

Sumber: @filmgarden

\section{Gambar 4. Dua Buah Pisang Saling Disandarkan}

Gambar 4 dimaknai sebagai aktivitas cuddling (berpelukan atau spooning) oleh para informan. Cuddling berarti "an intimate act that shows love" (King, n.d.). Cuddling dapat berupa tindakan seperti berpelukan, berpegangan tangan, menyentuh punggung seseorang atau berciuman dengan memegang wajah seseorang.

Dengan penggunaan analogi dua buah pisang, beberapa informan kesulitan memaknai gambar 4. Tetapi, beberapa informan lainnya memaknai aktivitas tersebut dilakukan oleh pasangan sesama jenis. Dua buah pisang yang berdampingan sebagai penanda bahwa aktivitas tersebut dilakukan oleh pasangan sesama jenis, dilihat dari asosiasi buah pisang sebagai bentuk analogi visual organ intim laki-laki (penis). 
Pasangan sesama jenis atau kelompok LGBT dianggap menyimpang dari norma yang ada pada tatanan masyarakat Indonesia. Hal tersebut didukung dengan konsep heteronormativitas sehingga masyarakat cukup sulit menerima adanya orientasi seksual yang lain.

Sehingga, meskipun menurut para informan aktivitas cuddling merupakan hal yang sudah biasa, namun aktivitas tersebut masih dianggap tabu. Apalagi jika yang melakukan adalah pasangan homoseksual, yang mana kelompok LGBT sudah mendapat pertentangan dari awal oleh beberapa kelompok masyarakat Indonesia yang menganggap hal tersebut menyimpang.

\section{Visual Menggenggam Pisang dan Bias Gender Masturbasi}

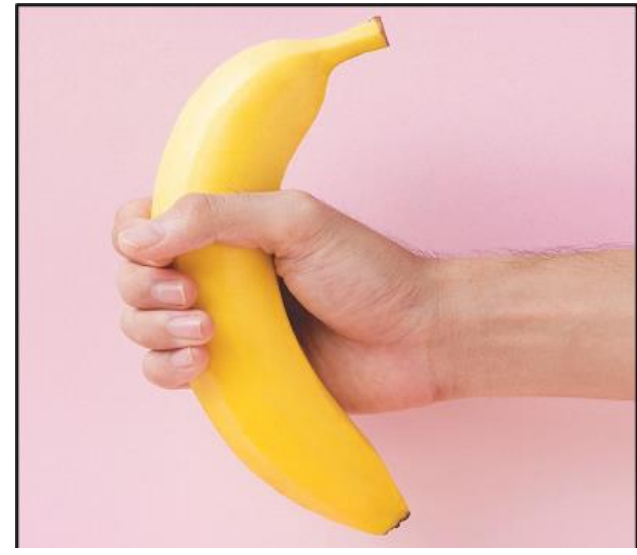

Sumber: Gossel, 2020

Gambar 5. Buah Pisang Digenggam

Pada gambar 5, beberapa informan berpendapat bahwa gambar tersebut tidak merepresentasikan suatu hal, melainkan hanya buah pisang yang sedang dipegang laki-laki. Sedangkan untuk beberapa informan lain, gambar 5 dimaknai sebagai penis (asosiasi buah pisang) yang sedang dimainkan atau bisa disebut dengan aktivitas hand-job.

Hand-job yang mana merupakan salah satu jenis masturbasi merupakan "kind of sexual manipulations of the genitals or of an erogenous zone which has no partner as an indispensable prerequisite, and the aim of which consist in the direct discharge of sexual excitation" (Tausk, 1951).

Ketabuan juga masih melingkupi aktivitas seksual berupa masturbasi ini. Pada abad 18 masturbasi disebut sebagai 'penyakit baru' yang memerlukan tindakan medis. Dilanjutkan pada abad 19, terdapat isu munculnya kelompok anti-masturbasi (hai.grid.id, 2016). Hingga saat ini di Indonesia sendiri, aktivitas tersebut masih menjadi hal yang tabu untuk dilakukan maupun untuk diperbincangkan.

Padahal, masturbasi bisa menjadi alternatif untuk memuaskan diri dan juga sebagai upaya untuk lebih mengenali bagian tubuh pada individu. Namun, selain masih tabu, masturbasi juga sangat berbasis gender. Dalam artian, laki-laki lebih dilazimkan untuk melakukannya dibandingkan perempuan.

\section{Keengganan Informan Memberikan Likes atau Comments dan Sharing Terbatas pada Konten Seksualitas}

Para informan yang menerima dan memaknai penggunaan analogi visual seksualitas berupa makanan oleh influencer Instagram kerap kali hanya menggunakan medium tersebut untuk sekadar mencari tahu. Seperti yang diungkapkan Informan 1 'NA' bahwa ia lebih nyaman 
membaca unggahan-unggahan seksualitas yang ada pada akun influencer. Ia juga biasanya hanya memberi likes pada beberapa unggahan yang menurutnya menarik. Sedangkan untuk berkomentar, ia tidak tertarik melakukannya karena sudah banyak yang mengajukan pertanyaan dan hal tersebut sudah cukup memperkaya informasinya.

Informan 2 'Salsha' juga mengatakan lebih tertarik membaca konten seksualitas, khususnya yang ada pada story atau highlight story karena menurutnya lebih kompleks dan interaktif. Selanjutnya, untuk likes, ia cukup jarang memberikannya pada unggahan-unggahan yang ada pada akun influencer Instagram. Namun untuk sharing, ia lebih memilih untuk berbagi secara terbatas bersama pasangannya melalui direct message. Ia beralasan bahwa mereka sama-sama mengikuti dan membaca konten tersebut, sehingga pembahasan menjadi lebih intens karena memiliki frame of reference yang sama.

Sedangkan, pendapat lain datang dari Informan 5 'Adel' yang mengatakan bahwa ia lebih sering memberi likes atau share saja. Likes diberikan sebagai upaya untuk memberi feedback dan apresiasi pada konten yang menarik. Ia juga melakukan share terbatas hanya pada teman atau orang pilihannya saja.

Penjabaran di atas dapat dihubungkan dengan masih adanya anggapan tabu pada topik atau konten seksualitas yang mereka terima. Kemudian, topik seksualitas yang kerap kali dilihat dari segi moralitas, yang mana menyebabkannya menjadi hal yang 'tidak pantas' jika dibicarakan secara terbuka. Sehingga, para informan lebih memilih untuk menerima informasi saja atau sekadar mencari tahu.

\section{PENUTUP}

Melalui penjabaran yang telah dilampirkan pada bab dan sub-bab sebelumnya, dapat diketahui bahwa penelitian ini bertujuan untuk menganalisis penerimaan pengguna Instagram terhadap analogi visual seksualitas dengan makanan oleh influencer Instagram.

Sehingga, pada penelitian ini dapat ditarik kesimpulan untuk menjawab rumusan masalah (a), yaitu informan memaknai gambar donat sebagai analogi visual vagina dilihat melalui karakteristik donat yang memiliki lubang di tengahnya yang mana memunculkan stereotip pada bentuk dan warna ideal dari organ tersebut. Meskipun responden mengaku merasa nyaman melihat ragam ilustrasi visual vagina, baik saat vagina dianalogikan dengan donat maupun saat vagina digambarkan dalam bentuk sketsa, namun menariknya responden mengaku merasa 'risih' saat peneliti menyebut kata vagina karena anggapan bahwa vagina merupakan bagian tubuh yang menjijikkan dan seringkali ditutupi. Selanjutnya, pisang dimaknai sebagai analogi visual penis karena memiliki bentuk yang lurus dan panjang. Hal tersebut membentuk stereotip pada bentuk dan ukuran penis setiap laki- laki sama.

Sedangkan berkaitan dengan rumusan masalah (b), didapatkan hasil bahwa informan memaknai gambar lubang donat dimasuki pisang sebagai bentuk penetrasi pasangan heteroseksual yang mana anggapan bahwa hubungan seksual yang ideal hanya terjadi di antara pasangan lakilaki dan perempuan saja. Lalu, ketika dua buah pisang saling disandarkan, para informan memaknai analogi tersebut sebagai aktivitas cuddling dan informan memaknai aktivitas tersebut dilakukan oleh pasangan homoseksual karena adanya anggapan dua pisang sebagai dua penis. Kemudian, ketika terdapat gambar buah pisang digenggam, para informan memaknai sebagai aktivitas hand-job dan aktivitas tersebut masih berbasis gender.

Sehingga, analogi visual seksualitas diterima dan diinterpretasi oleh para informan melalui 
konsep heteronormativitas yang berkembang dalam masyarakat Indonesia. Aktivitas seksual dianggap menjadi ideal jika yang melakukan adalah laki-laki dan perempuan. Menariknya, jika terdapat studi yang mengatakan bahwa terdapat peningkatan pada homophobia dan transphobia di Indonesia, namun ketika homoseksualitas digambarkan melalui analogi visual makanan, para informan tidak memperlihatkan adanya kebencian atau ketakutan, serta tidak meniadakan keberadaan kelompok LGBT di Indonesia. Hal tersebut terjadi karena bentuk penggunaan analogi yang berbeda, dapat menimbulkan reaksi yang berbeda pula. Dengan ini terlihat bahwa beberapa informan memaknai analogi visual seksualitas dengan makanan sesuai dengan praktik wacana dan budayanya masing- masing.

\section{DAFTAR PUSTAKA}

Arianita, A. (2012). Heteronormativitas dalam Novel Gerhana Kembar sebagai Sastra Populer Karya Clara NG: Tinjauan Sosiologi Sastra. Universitas Indonesia.

Djiwandono, S. E. W. (2008). Pendidikan Seks untuk Keluarga. PT Indeks.

Ernawan, Y. (2009). Buku Ajar Gender \& Seksualitas. PT Revka Petra Media.

Fitriyani. (n.d.-a). 4 Tipe Mr. P, Bentuk Serupa Tapi Tak Sama. Apa Bedanya? TheAsianParent. Retrieved May 8, 2020, from https://id.theasianparent.com/berbag ai-macam-bentuk-penis.

Fitriyani. (n.d.-b). Mengapa Kulit Kemaluan Lebih Gelap Dibanding Bagian Tubuh Lain? Ini Penyebab dan Cara Mengatasinya. TheAsianParent. Retrieved May 27, 2020, from https://id.theasianparent.com/penyebab-warna-vagina-berbeda

Foucault, M. (1976). The History of Sexuality: Volume 1: The Will to Knowledge. https://books.google.co.id/books?hl= nd\&pg=PT15\&dq=foucault+on+sex $\mathrm{id} \& \mathrm{lr}=\& \mathrm{id}=5 \mathrm{xSfDwAAQBAJ} \& \mathrm{i}=\mathrm{f}$ Kg6iRU9RF9gEn5kff4EzVDs\&redir\%0A_esc=y\#v=onepage\&q\&f=false\%0A

Frownfelter, A. (2010). Flower Symbolism as Female Sexual Metaphor Flower Symbolism as Female Sexual Metaphor [Eastern Michigan University]. http://commons.emich.edu/honors/238?utm_source=commons.emich.edu\%2Fhonors\%2F23 8\&utm_medium=PDF\&utm_campaign=PDFCoverPages

hai.grid.id. (2016). Sejarah Masturbasi: Dulu Menyimpang Sekarang Jadi Ruang Seksualitas yang Normal. Hai.Grid.Id. https://hai.grid.id/read/07351273/sej arah-masturbasi-dulumenyimpang- sekarang-jadi-ruang-seksualitas- yang-normal

Halstead, J. M., \& Reiss, M. (2004). Sex Education: Nilai Dalam Pendidikan Seks Bagi Remaja; Dari Prinsip Ke Praktek (Nisak, Kuni, \& Trans (Eds.)). Alenia Press.

Hongxu, H., \& Guisen, T. (1990). A sociolinguistic view of linguistic taboo in Chinese. International Journal of the Sociology of Language, 81.

Ida, R. (2014). Metode Penelitian Studi Media dan Kajian Budaya. Prenadamedia Group.

Jones, K., Eathington, P., Baldwin, K., \& Sipsma, H. (2014). The Impact of Health Education Transmitted Via Social Media or Text Messaging on Adolescent and Young Adult Risky Sexual Behavior: A Systematic Review of The Literature. Sexually Transmitted Diseases, 41(7), 413-419.

King, T. (n.d.). Difference Between Cuddling \& Spooning. Datingtips.Match.Com. Retrieved May 
10, 2020, from https://datingtips.match.com/differen ce-between-spooning-cuddling8672161.html

Pakasi, D. T., \& Kartikawati, R. (2013). Antara Kebutuhan dan Tabu: Pendidikan Seksualitas dan Kesehatan Reproduksi bagi Remaja di SMA. Jurnal Makara Seri Kesehatan, 17(2), 79-87.

Perkumpulan keluarga berencana indonesia. (2016). Pengertian Seks Dan Seksualitas. Https://Pkbi-Diy.Info/. https://pkbi-diy.info/category/seksualitas/

Redaksi. (2018). Perihal Seksualitas, Masyarakat Indonesia Sangat Munafik. Sejuk.Org. https://sejuk.org/2018/07/14/perihal-seksualitas-masyarakat-indonesia-sangat-munafik/

Rushton, J. P. (1988). Race differences in behaviour: A review and evolutionary analysis. Personality and Individual Differences, 9(6), 1009-1024. https://doi.org/10.1016/01918869(88)90135-3

Safita, R. (2013). Peranan Orang Tua dalam Memberikan Pendidikan Seksual pada Anak. EduBio, 4(2), 32-40. https://doi.org/10.1017/CBO9781107415324.004

Shanti, N. K. A. P. (2015). Reception Analysis Terhadap Representasi Perempuan Bertato di dalam Foto Akun Instagram. Universitas Airlangga.

Suhari, I. (2011). Pendidikan Seks untuk Anak: Tabu atau Perlu? Kompasiana.Com. tps://www.kompasiana.com/iswadi\%0A.suhari/550ab27f8133112e14b1e1db/ pendidikanseks-untuk-anak-tabu- atau-perlu?page $=$ all $\% 0 \mathrm{~A}$

Tausk, V. (1951). On Masturbation. The Psychoanalytic Study of the Child, 6(1), 61-79.

Tiggemann, M., Martins, Y., \& L, C. (2008). Beyond muscles: Unexplored parts of men's body image. Journal of Health Psychology, 13(8), 1163-1172.

Tirtawinata, C. M. (2016). Importance of Sex Education Since Early Age for Preventing Sexual Harassment. Humaniora, 7(2), 201-209.

Wargadiredja, A. T. (2017). Pendapat Orang-Orang Agar Pendidikan Seks di Indonesia Tak Kaku Lagi. Vice.Com. https://www.vice.com/id_id/article/q kmd5p/pendapat-orang-orang-agarpendidikan-seks-di-indonesia-tak- kaku-lagi. 